\title{
Manifesto para ampliação das vozes e das notícias no radiojornalismo brasileiro
}

\author{
Luciano Victor Barros Maluly (USP) ${ }^{1}$
}

\section{Resumo}

Este artigo revela as possibilidades de abertura no trabalho de reportagem por meio de um manifesto para a ampliação das fontes e das notícias no cotidiano da cobertura radiojornalística, fazendo do repórter um agente participativo no processo de democratização dos meios de comunicação de massa.

Palavras-chaves: Radiojornalismo; democracia; repórteres; fontes

\section{Abstract}

This article discloses the possibilities of opening of the news article work by means of a manifest for magnifying the sources and the news in the daily radiojournalistic covering, making the reporter a participative agent in the process of democratization of the mass-media.

Keywords: Radiojournalism; democracy; reporters; sources 


\section{Introdução}

O encontro com o público é o momento mágico idealizado pelos profissionais que desejam um processo democrático pelo rádio, sem restrições na escolha das vozes e das notícias que alimentam os programas jornalísticos. Nas principais emissoras do país, o predomínio é de quem fala (o jornalista) e do que se fala (notícias padronizadas), prática que conduz a um noticiário cerceado pela simples semelhança dos fatos, de quem precisa ser igual, de quem fala a mesma coisa, para não estar "por fora" dos assuntos que interessam aos "proprietários" da notícia.

Fatos ilustrados pelos que possuem direito ao microfone, como os políticos, os jogadores de futebol, os artistas de telenovela ou mesmo aquele especialista que já sabe a reposta, mesmo sem a pergunta. Vozes selecionadas pelo repórter que, pela proximidade, disponibiliza o espaço a quem já conhece, concedendo à fonte o direito adquirido, no sentido privilegiado de "eu posso falar, por que já concedi uma entrevista ou uma informação". Credibilidade assegurada pelo interesse, pelo encontro periódico, pela camaradagem, enfim, pela cumplicidade. Fale, fale, ocupe o tempo concedido pelo direito assegurado, afinal você está por cima, é poderoso e o público já te conhece. É fácil encontrar essa gente que ocupa os espaços da (e na) imprensa. Então, torna-se desnecessário ao repórter procurar quem realmente precisa falar, aquele que procura soluções, que luta contra os poderosos. Excluído denominado, carinhosamente, de ouvinte ou tratado, assustadoramente, como uma fonte imprevista.

Mas, nem sempre é assim. Torna-se pior quando a distância também completa a prática do mais fácil, perpetuada pela abertura ao interesse da imprensa, que implanta as suas notícias pelas vozes dos locutores e dos repórteres brasileiros, como também assegura a suas fontes um espaço garantido, sem contestação do repórter, que as consideram seguras, justamente, pela credibilidade conquistada pela fonte produtora. Acordo definido pelo falso crédito e pelo poder adquirido, implantando o medo na abertura da programação para o desconhecido, porque ele não fala direito, não é poderoso e talvez possa atingir a emissora, os jornalistas, os poderosos pelos berros, porque ele grita alto, ele precisa gritar mais alto, por que ninguém 
nunca o ouviu ou deixou falar, mesmo pelo telefone, dos problemas que ele vive diariamente no campo ou na cidade.

São pessoas que precisam do repórter por perto, na mesma proporção das personalidades. Difícil missão para quem está acostumado com os espaços já definidos pela pauta pronta, estabelecida pela atual prática jornalística. Andar pelas ruas ou pelo mato é desconfortável, justamente, pelo encontro com o desconhecido. O imprevisto torna-se a tônica da pauta. Mas o repórter é lutador, está cansado de ouvir as mesmas fontes. Procura agora mesclar as fontes. Fica conhecido das pessoas, por estar sempre presente. A necessidade de espalhar notícia passa por ele. A pergunta "Você viu o repórter?" é logo respondida com "Hoje de manhã ainda não, mas espera um pouco, porque ele passa sempre lá pelas duas da tarde. Ele também deixou o telefone. Se for urgente, ligue para ele. O telefone está ali no cartaz da rádio grudado na parede." Agora, a população já sabe que o repórter está disponível.

O confidente está próximo. Agora, não são só as celebridades que possuem direito na programação jornalística. A voz do desconhecido também está presente. Qualquer um pode falar com o repórter, contando o que realmente acontece diante das filas dos hospitais, do convívio das escolas públicas, da insegurança diária pela ausência de policiamento, da sujeira espalhada pelas ruas, do trabalhador que luta por um pedaço de chão, exemplos de descaso de uma política que afunda os projetos individuais e coletivos do povo brasileiro. Enfim, são os problemas diários vividos pelo homem comum que precisa espalhar, por meio de um confidente, as (in) justiças que acontecem no país.

Ele precisa do repórter, desse alguém que faça a sua voz ser ouvida ou que, pelo menos, relate o acontecimento para as outras pessoas. Muitas vezes, esse cidadão tem medo de se comprometer ou de ser perseguido. Não pode falar. Por isso, fica quieto, como um paciente no hospital, para ser atendido ou, como um empregado, para não sofrer punições. Mas os olhos do repórter estão atentos. Ele logo observa os problemas, fala pelo outro. Mantém-se atento ao desenrolar das situações. Observa a estrutura, as condições de trabalho ou a situação do local, ouve as partes, analisa os documentos. Ninguém quer falar, não tem acesso aos documentos, mesmo assim, seus olhos dirigem as palavras reveladas pela... 


\section{Boca}

Momento importante para a perpetuação de um jornalismo diferenciado, no sentido de falar outros sons por meio de notícias variadas. Informações traduzidas pelo universo dos acontecimentos. Pautas desenvolvidas pelo contato com o público. O repórter continua alerta. Seleciona os assuntos predominantes, que realmente interferem no cotidiano das pessoas. 0 noticiário está aberto, sem vínculo com as notícias pré-determinadas. Mas nada foge da boca do repórter. Sua presença é fundamentada pelo testemunho, sua ausência determina que o outro tem direito ao testemunho. Desta forma, ele está sempre presente, porque o público é a extensão de sua boca, de sua voz, de sua profissão.

Inicia-se a democracia nos programas radiojornalísticos. As emissoras brasileiras, inclusive as comerciais ligadas aos grandes grupos de comunicação, agora garantem ao repórter a condição de agente participativo, sujeito conhecido pela população, sujeito atuante para quem se pode falar ou ligar sem ser menosprezado por estar fora do grupo de privilegiados, dos que têm direito ao microfone todos os dias. As pressões vão existir, porque é "necessário" falar dos lugares e de quem habita neles. É possível vigiar o governo, vasculhar a vida das celebridades, incentivar os eventos e, ainda assim, relacionar os assuntos que massacram ou auxiliam o povo brasileiro. Basta vontade.

O conteúdo é alimentado por matérias selecionadas pela equipe de jornalismo e cabe ao condutor do processo de construção da notícia determinar o que é de interesse público. Ganha-se a principal função exercida pelo jornalista - a de repórter, do profissional que determina as diversas fases da cobertura, desde a coleta até a transmissão. Partindo da origem do acontecimento, as fases de coleta, seleção, apuração dos dados, bem como as de elaboração, checagem e finalização da matéria, sem se restringir ou se limitar, ou mesmo se condicionar, à atual crise do radiojornalismo, fundamentada pela simples reprodução do que já foi dito.

Quebram-se as portas do jornalismo brasileiro pela divulgação radiofônica do que realmente acontece por dentro da vida das pessoas, 
principalmente daqueles que necessitam de um teto, de uma terra, de um professor, de comida, de atendimento médico, de lazer, enfim, de conforto advindo de seu próprio suor. São bocas calejadas que merecerem respeito, que podem ter no jornalista de rádio uma extensão da angústia e da alegria, do que realmente os outros precisam saber. Se o repórter pode (re) transmitir o que se passa com as personalidades, também é de sua responsabilidade relatar a vida cotidiana, posicionando-se criticamente diante dos acontecimentos, possibilitando a atuação direta pela passagem (contato), sem discriminar a fonte conforme a posição adquirida no contexto social.

A facilidade é imensa quando o jornalista participa diretamente das fases de construção da notícia. Os fatos se revelam na seqüência, sendo o repórter também protagonista do acontecer. Ele amplia o que está em documentos ou mesmo na fala dos entrevistados. Sente-se seguro, observando uma saída integral para relato. Detalhes são acrescentados pela percepção, podendo assim interpretar o que já foi ou está sendo dito ou mesmo o que já aconteceu ou está acontecendo.

O repórter também é fonte. As impressões precisam ser transmitidas. Ele é o ouvinte, que se projeta no acontecimento, como protagonista que relê a história. Fato ampliado pela boca, que pode ser ouvida em qualquer lugar do mundo. Estar presente, como as histórias que as pessoas contam quando chegam em casa. Sabe o que aconteceu? Relato das passagens da vida. Desejo de dividir/repartir certos momentos. Multiplicar a presença como se o outro estivesse presente. Incorpora-se a história de alguém. Conviver com o sentimento alheio. Quem não chorou ou riu quando um colega ou parente contou determinada passagem.

Boca que integra os demais sentidos; boca que revela o cotidiano; boca que não é feita apenas para ler em voz alta, mas para revelar os acontecimentos que fazem parte da rotina de todos nós; boca que passeia pelo terreno; boca que não fica sentada em frente ao computador. Podem chamar de repórter vigilante ou ronda. Que seja! O lugar do repórter de rádio é estar em todos os lugares, sem ficar preso na redação, fazendo entrevistas pelo telefone ou reescrevendo matéria.

Para quem não acredita, o rádio está sempre sendo vigiado. Um dia passei por uma banca de revista. O proprietário estava irritado com uma 
emissora paulistana, vizinha da banca. Um repórter anunciara que o tempo estava apenas nublado em São Paulo. Logo o proprietário disse: "Choveu o dia inteiro aqui. É brincadeira. Hoje à tarde, eu irei à rádio reclamar". Curioso, voltei no outro dia. "Como foi?", eu perguntei. "Fui até a emissora. Chamei o editorchefe. Ele demorou, mas veio. Logo perguntou. 'Pois não?' Contei o fato e disse: Fale para seu repórter olhar pela janela. Me despedi e fui embora", respondeu o ex-ouvinte da rádio. Outro dia também fui ao sítio de um pequeno agricultor. Ele estava ouvindo o radiojornal local. "E aí, o programa está legal?". Logo levei uma indireta dele. "É! Eles estão lendo o jornal de hoje”. E emendou: "Eu quero ouvir as notícias da minha região. O que aconteceu com o meu vizinho, com a minha terra".

Fatos assim acontecem em todo o Brasil. É que o repórter está ficando mal-acostumado com a internet, com o jornal, com a televisão, com a facilidade. E é triste pensar que essa prática continua em várias emissoras, como se o rádio no Brasil, nesses 85 anos, não passasse por uma...

\section{Revolução}

O repórter, como sujeito que se relaciona com as pessoas, interage diante das reclamações, angústias e alegrias. Fora de casa (redação), o jornalista ouve (vê/lê) outras informações, opiniões, enfim, busca interpretações para as notícias. A reportagem está aberta, porque ele precisa sair, gritar, falar sobre o que está ao seu redor, sendo o "boca-maldita", o "boca-santa", o "bocasuja", a boca das bocas que não falam ou o transmissor das bocas que desejam falar. Boca que anda pela rua cheia de lixo, que atravessa a faixa junto com o motorista que desrespeita o pedestre, que espera nas filas diárias dos bancos, da prefeitura e dos lugares que desrespeitam a população, que navega pelos rios poluídos das grandes metrópoles, que come merenda, que acompanha quem está sem nada (terra, rua, escola) ou quem convive com o descaso diante das dificuldades ou das necessidades de cada um.

O jornalista desenvolve diversas funções numa emissora de rádio, sendo a de repórter a mais ampla, essência da profissão de jornalista. Atividade que independe da cobertura de outros jornalistas (meios), sendo o campo de visão ilimitado. É importante para o editor prestar muita atenção nesse trabalho, 
possibilitando a cobertura para as notícias cotidianas que interferem ou repercutem, diretamente, no cotidiano da população. No radiojornal, ao privilegiar a reportagem, criam-se meios para a integração ou participação dos envolvidos ou interessados no debate perante a notícia. Credibilidade conquistada pela confiança, pela disposição da equipe e pela linha editorial que possui a abertura da pauta. Prevalece a matéria constituída, com participações e relações que vão além da equipe de reportagem. Notícias que incluem o público, integrando-o ao processo. Aqui a boca é única. O locutor (ou o repórter) interpreta a notícia que também foi interpretada pelo público. A distância diminui, assim como o poder das empresas jornalísticas. O que faz o editor? Permite a abertura da pauta, as produções da equipe de jornalismo, a contribuição dos colaboradores e do público, refletindo, pelo som, as ações determinadas conforme o desenrolar dos fatos.

O jornalista de rádio não fica parado reescrevendo, a todo o momento, matérias que recebe, principalmente, da internet. Seu lugar de trabalho é o universo do acontecimento, o ambiente do outro, permeado pelas situações que determinam a própria essência da profissão. Ele precisa ouvir as pessoas, narrar o acontecido, sentir na pele a existência de algo que preenche o mesmo vazio dos brasileiros que estão sem-espaço para moradia, trabalho ou estudo. Assim, um fato só tem origem quando alguém está presente. Neste sentido, o repórter ocupa diversos lugares ao mesmo tempo, justamente porque está sempre presente, por si ou pelo outro, que é a sua própria extensão. O jornalista concede à fonte o direto de possuir o mesmo poder concedido a ele pela sociedade. Naqueles momentos, todos são repórteres por um único meio.

Não há mais passado porque, mesmo quando não é possível instalar uma emissora ou quando o repórter não está diretamente presente, tem-se a oportunidade de gravar os momentos importantes da coletividade. São arquivos vivos das situações que auxiliam o trabalho de reportagem, justamente por possuir um registro sonoro dos acontecimentos. Nada mais é perdido, sendo a versão conduzida pelo falante. Fica, assim, a contribuição para a cobertura, indícios que conduzem o repórter ao local, dividindo as responsabilidades, reforçando a credibilidade e a mediação pelo confronto do que se fala com o que se vê. 
"Autonomia para os jornalistas". Frase libertadora que vai possibilitar a ocupação do radiojornalismo pelo personagem comum, que agora vai poder cobrar do repórter atuações diante da construção de um País que seja justo e igualitário, pelo menos diante das atitudes determinadas pela seleção de pauta.

Concessão pelo ato de se comunicar, de poder conversar com outro, de disponibilizar o universo sonoro para quem precisa dele, ampliando os canais que levam à democracia. Radiojornalismo popularizado pelo movimento dos repórteres espalhados pela terra em busca da notícia. Meieiros, parceiros no sentido aberto de dividir os "atributos" com as fontes, não detendo sozinho o poder diante da escolha de quem pode ou deve participar da cobertura. Responsabilidade dividida pelo direito de informar, de...

\section{Ensinar}

A revolução das emissoras de rádio, exemplificada pela simples diversidade do cotidiano, também modifica a prática do ensino de radiojornalismo nas universidades. Os alunos são estimulados por exercícios contínuos de integração com o cidadão comum, como também pela construção de radiojornais ambientados fora do estúdio de rádio. Consideram-se as relações pela proximidade com a fonte, reforçando a presença e o contato. Diminuem-se as distâncias e as ilusões proporcionadas pela possível comodidade das redações e dos estúdios. Processos jornalísticos conduzidos pela flexibilidade, pelo posicionamento diante do imprevisto, para descobrir o rádio e o jornalismo pela simples coragem de reportar fatos às (pelas) pessoas.

O ensino se estende pela prática jornalística. Nada impede que os repórteres auxiliem a população na utilização de aparatos simples como o telefone e o gravador. Muitas vezes, num pequeno contato, o jornalista pode, primeiro, pedir para as pessoas transmitirem (e/ou gravarem) os principais acontecimentos que influenciam diretamente o cotidiano da comunidade. Aqui também é observada a "seleção de notícias" como uma fase essencial para a cobertura jornalística, já que nem tudo que acontece é de interesse coletivo. $O$ repórter revela que entrevistas são importantes, assim como a captação do som ambiente e o relato do repórter, que conduz, por sua fala, as situações do 
ocorrido (mescla da fala do repórter, da fala dos entrevistados e do som ambiente).

A reportagem contínua facilita a compreensão pelo ouvinte que observa o ocorrido pela seqüência sonora dos fatos, assim como facilita o trabalho do falante e também do pessoal da emissora, porque indiretamente diminui os recortes no processo de edição, auxiliando na compreensão do conteúdo que está sendo emitido. A assinatura do autor também é necessária porque, como eventual emissor, o autor se torna responsável pelas declarações.

O repórter da emissora, assim como faz com as entrevistas, pode transmitir a mensagem na íntegra ou mesmo utilizar trechos das gravações, sempre citando o autor. O relato de quem está presente também permite ao repórter variar (ou ampliar) as formas de captação, criando outro ambiente sonoro, além das já conhecidas entrevistas.

Popularizar a reportagem por meio da aprendizagem da técnica jornalística é um processo difícil, mas possível, desde que ocorra um trabalho que envolva as universidades e as emissoras de rádio. Profissionais e professores de radiojornalismo são peças fundamentais que conduzem o ensino da técnica pela conscientização, pelo esclarecimento de que liberdade e responsabilidade são condições determinantes e inseparáveis para a atividade jornalística.

Professores oferecendo cursos de extensão, indo aos locais onde o público está, ensinando o processo jornalístico para a população e conversando com as pessoas sobre os problemas da imprensa; os repórteres, em breves momentos, mostrando a sua técnica, revelando os meandros da profissão, no sentido de ensinar pela própria experiência; o público, saindo da posição de ouvinte e entrevistado, aproximando-se dos profissionais, perguntando sobre as possíveis formas de ação e/ou colaboração; ambos integrados na busca de um jornalismo democrático.

\section{Considerações finais}

A atuação conjunta ocorre quando cada um se disponibiliza a participar do processo de construção e transmissão do conhecimento. Situação possível pelo desejo individual de abertura das universidades, das emissoras de rádio e 
das comunidades, no sentido de que as pessoas conversem, troquem experiências, vivenciem o universo alheio.

O rádio é um meio simples e barato, sem os problemas de uma cobertura pela televisão e pelo impresso. Por isso, peço que todos nós, que trabalhamos com radiojornalismo, possamos levar ao público a realidade de nosso país, permitindo que as pessoas participem das coberturas jornalísticas. Mas isso somente será possível por meio da ampliação da agenda dos programas das emissoras de rádio, mesclando as notícias de interesse dos poderosos com as de interesse dos excluídos, possibilitando, assim, um aumento na fiscalização diante da omissão dos setores públicos e privados. Ou seja, o jornalista pode sim possibilitar o acesso da população aos meios de comunicação de massa, vinculando a mensagem ao que é de interesse coletivo, variando e ampliando as formas de conversação e, principalmente, diferenciando o conteúdo das programações radiojornalísticas conforme a emissora. Chega de ouvir os mesmos sons, as mesmas vozes, as mesmas notícias.

Parece pedir muito para os jornalistas brasileiros, mas é necessário, neste momento, modificar a estrutura das emissoras brasileiras de rádio, principalmente porque não há mais justificativa para monopólio das vozes e das notícias diante da imensa abertura proporcionada pelos aparatos tecnológicos. Qualquer pessoa pode emitir uma informação, assim como entrar na programação ou mesmo colaborar com a equipe de reportagem, como já dissemos aqui. Uma das alternativas é criar espaços para a participação popular por meio de um projeto de acesso ao radiojornalismo. E tenho certeza que o silêncio se transformará em notícia, pelos berros que ecoam em todo o Brasil. 


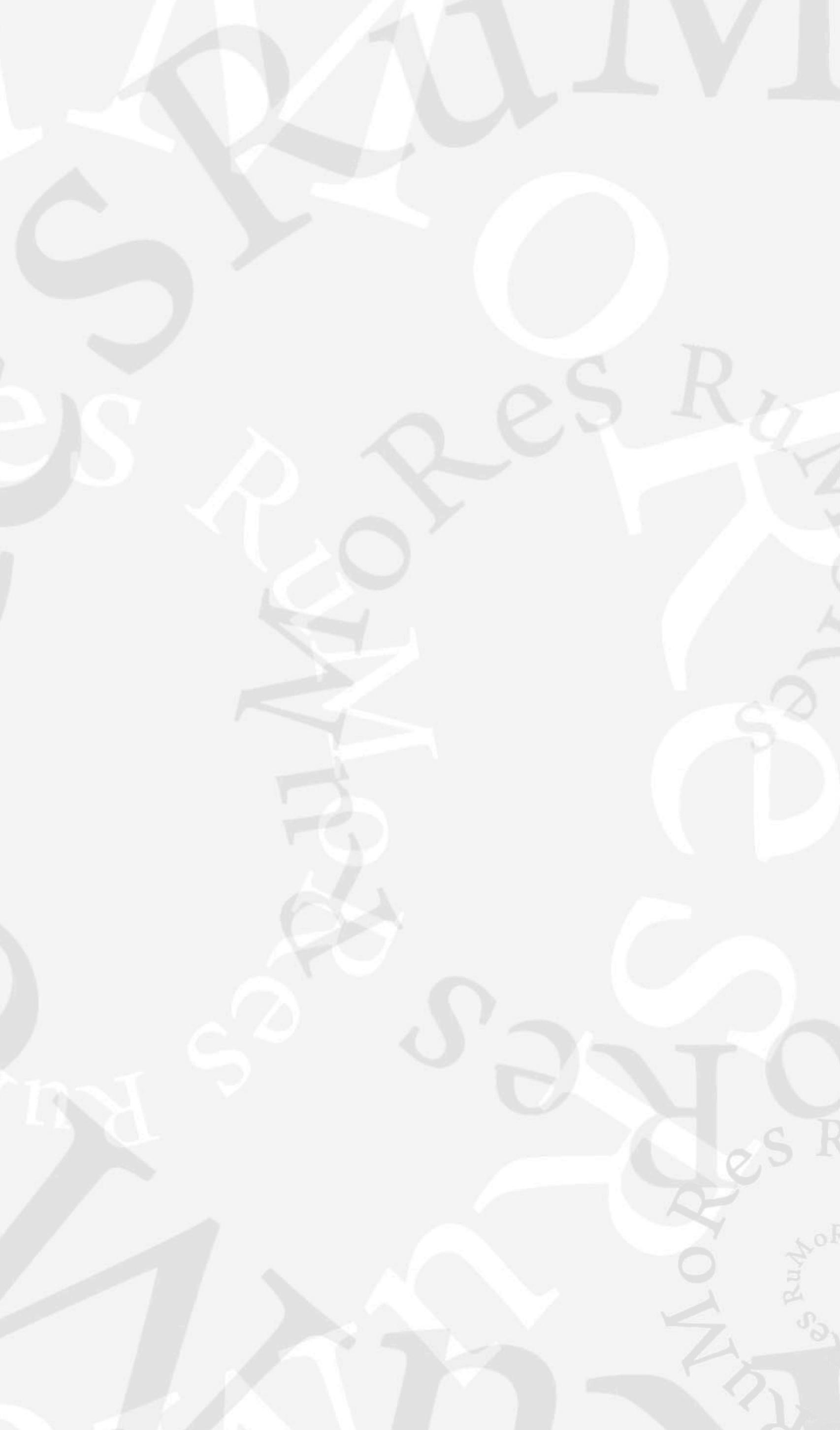




\section{Referências bibliográficas}

BOHM, David. Diálogo: comunicação e redes de convivência. São Paulo: Palas Athena, 2005.

BRECHT, Bertold. Cinco maneiras de dizer a verdade In: Revista Civilização Brasiliense. Rio de Janeiro, 1966, número 5.

MACHADO, Arlindo; MAGRI, Caio \& MASAGÃO, Marcelo. Rádios Livres: a reforma agrária no ar. São Paulo: Brasiliense, 1986.

MEDITCH, Eduardo (org.) Teorias do rádio. Florianópolis: Insular, 2005.

ORTIZ, Renato. A moderna tradição brasileira. São Paulo: Brasiliense, 1993.

PARK, Robert E. A notícia como forma de conhecimento. In: Meios de Comunicação de Massa. Organização de Charles S. Steinberg. São Paulo: Cultrix, 1966.

PARROM, Milton. O radiorrepórter. IN Revista USP/Coordenadoria de Comunicação Social. Universidade de São Paulo - Número 1 (março/maio de 1989). São Paulo: USP/CCS,1989.

PIERNES, Guillermo. Comunicação e desintegração na América Latina. Brasília: Editora Universidade de Brasília, 1990.

POPPER, K. O racionalismo crítico na política. Brasília: Editora Universidade de Brasília, 1981.

SANTORO, Luiz Fernando. Rádios Livres: o uso popular da tecnologia. In Revista Comunicação e Sociedade. Ano III. Número 6. São Bernardo do Campo: Cortez Editora, setembro de 1981.

SHAFFER, Murray R. Rádio Radical. in BENTES, Ivana \& ZAREMBA, Lílian (Orgs). Rádio Nova: constelações da radiofonia contemporânea. Rio de Janeiro: UFRJ, ECO, Publique, 1997.

\footnotetext{
${ }^{1}$ Doutor em Ciências da Comunicação e professor de radiojornalismo, ambos na ECA/USP.
} 